\title{
ANALISIS KEBIJAKAN FISKAL DAN IMPLIKASINYA KEPADA PEREKONOMIAN INDONESIA: ANALISIS KESEIMBANGAN UMUM
}

\author{
Wawan Hermawan \\ CEDS FEB Universitas Padjadjaran Bandung \\ Jl. Cimandiri No. 8 Bandung. Telp. 022-4204510 \\ Email: w.hermawan@unpad.ac.id
}

\begin{abstract}
The economy cannot be separated from the role of government spending in stimulating the economy. Fiscal policy is government's tool to intervene in the economy, could change for the better economy or even make the economy into a recession. On the other hand, economic activity over the impact of greenhouse gas contribution, so the impact on global climate change. Therefore, a certain sectorspecific fiscal policies have considerable impact in influencing greenhouse gases. This study aims to provide an analysis of fiscal policy scenarios that can affect greenhouse gases, so that could explain what sector-specific fiscal policies that can increase the risk of climate change. This research uses the model of Computable General Equilibrium (CGE) based fiscal policy held by the Ministry of Finance of the Republic of Indonesia named AGEFIS (Applied General Equilibrium Model for Fiscal). The scenario is to decrease fosil fuel subsidy that can produce CO2 emision. The results shows that decreasing fossil fuel subsidies can reduce the $\mathrm{CO} 2$ emission, but with high consequences. The consequences are the economic growth seen to fall, household wealth declined and the real consumption levels decrease.
\end{abstract}

Keywords: Fiscal Policy, Climate change, CGE, AGEFIS, CO2

\section{PENDAHULUAN}

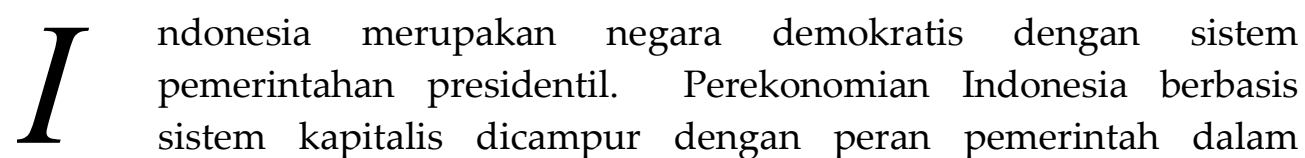
beberapa aspek ekonomi strategis, seperti energi, telekomunikasi dan transportasi. Setelah masa reformasi, peran pemerintah mulai dikurangi dengan memberikan wewenang individu lebih besar dalam membawa perekonomian menuju keseimbangan alaminya. Walau bagaimanapun, QE Journal | Vol.05 - No. 02 June 2016 - 75 
peran pemerintah dalam mempengaruhi perekonomian masih besar. Hal ini tercermin dalam kebijakan fiskal dan moneter yang masih sanggup merubah pola perekonomian di Indonesia.

Struktur ekonomi Indonesia, telah masuk pada struktur negara industri. Hal ini terlihat pada kontribusi sektor industri pengolahan yang mempunyai kontribusi terbesar (25\% pada tahun 2010). Dilihat dari sisi penyerapan tenaga kerja di Indonesia, sektor pertanian masih merupakan sektor yang terbesar (38\% pada tahun 2010) walaupun dengan tren yang turun.

Kebijakan fiskal diakui banyak bermanfaat dalam meningkatkan perekonomian, terutama pada saat perekonomian mengalami pelambatan (Ismal, 2011). Kebijakan fiskal yang berlandaskan pada pengeluaran pemerintah dan pengenaan pajak memberikan stimulus terhadap perekonomian suatu negara. Demikian juga dengan Indonesia, kebijakan fiskal di bawah komando presiden telah melakukan berbagai kebijakan dalam mengawal perekonomian menuju tingkat keseimbangan dengan pertumbuhan ekonomi tertinggi.

Pertumbuhan ekonomi Indonesia yang tinggi banyak dibantu oleh berbagai kebijakan fiskal, seperti peningkatan penanaman modal asing (Fatah et.al., 2012) dengan menggunakan insentif pajak. Harapan dari adanya modal dari luar akan memicu trickle down effect dari akumulasi modal (Aghion and Bolton, 1997). Hal ini sebagai salah satu alasan terjadinya pertumbuhan ekonomi Indonesia dengan tingkat pertumbuhan yang bagus. Pada rentang waktu 1981-2010 pertumbuhan rata-rata pertumbuhan ekonomi per tahun ada pada kisaran 5,6\% atau 6,17\% jika tahun krisis ekonomi tidak dimasukkan. Oleh karena itu, Indonesia termasuk dalam negara yang masuk ke dalam kelompok negara-negara Keajaiban Asia (Asian Miracle Countries) (Stiglitz, 1996:1).

Ketika aktivitas ekonomi meningkat, maka penggunaan sumber daya akan lebih tinggi, termasuk sumber daya alam. Proses produksi akan menggunakan input dari faktor primer seperti tenaga kerja dan modal, input antara dan juga sumber daya alam yang berasal dari lingkungan alami. Perekonomian semakin tinggi tingkatnya, maka output yang dihasilkan dalam perekonomian juga akan semakin meningkat dan berdampak pada penggunaan sumber daya alam yang semakin massif, 
sementara kemampuan alam dalam menyediakan sumber daya sangat terbatas (UNEP, 2010).

Peningkatan aktivitas ekonomi secara langsung atau tidak langsung akan mempengaruhi kualitas lingkungan dimana perekonomian tersebut berjalan (Halkos, 2012). Dampak penggunaan input sumber daya alam sebagai faktor produksi berdampak terhadap lingkungan sebagai wadah raksasa untuk menampung sisa dari aktivitas ekonomi. Dampak lingkungan akan terasa baik dari media alam tanah, air maupun udara.

Sebagian PDB dikeluarkan oleh pengeluaran pemerintah dengan berbagai dampaknya pada sektor-sektor perekonomian di masyarakat. Halkos, (2012) menjelaskan akan adanya hubungan antara pengeluaran pemerintah dengan polusi pada 77 negara pada periode tahun 1980-2000. Jika PDB terbentuk oleh peran dari pengeluaran pemerintah, maka pengeluaran pemerintah mempunyai tanggung jawab juga terhadap polusi lingkungan.

Adanya fenomena pengeluaran pemerintah memicu adanya polusi udara, memberikan dampak atas peningkatan gas rumah kaca. Kontribusi dari $\mathrm{CO} 2$ sebagai kontributor yang tinggi untuk gas rumah kaca banyak disumbang oleh aktivitas ekonomi (Stern, 2006). Naiknya aktivitas ekonomi berdampak lurus terhadap naiknya gas rumah kaca. Oleh karena itu, pengeluaran pemerintah menjadi sebuah kunci dalam melakukan kontrol terhadap gas rumah kaca, dimana hal ini menjadi menarik untuk dikaji lebih jauh.

Menurut laporan yang dibuat oleh APEC (APEC, 2010), sumber gas rumah kaca yang terbesar adalah $\mathrm{CO} 2$ dengan pertumbuhan yang tinggi. Masih menurut laporan tersebut, sumber $\mathrm{CO} 2$ terbesar ada pada deforestasi yang hampir seperempatnya diikuti oleh $\mathrm{CO} 2$ yang bersumber dari bahan bakar fosil yang bersumber dari transportasi dan pembangkit energi listrik. Tingkat konsumsi energi di Indonesia yang digunakan sebagai sarana transportasi menggunakan sumber energi minyak bumi yang disubsidi oleh pemerintah. Pengeluaran subsidi pemerintah Indonesia lebih besar untuk memberikan subsidi energi dibandingkan untuk yang bukan energi. Seperti ditampilkan di Tabel 1, sepanjang tahun 2006 sampai dengan tahun 2012 pengeluaran untuk subsidi energi selalu lebih besar dibandingkan dengan subsidi bukan energi. Hal ini diperparah lagi apabila terdapat 
kenaikan hanya minyak dunia yang akan meningkatkan nilai subsidi yang harus ditanggung oleh pemerintah Indonesia.

Table 1. Indonesian Government Spending On Subsidies (\%)

\begin{tabular}{cccccccc}
\hline Subsidy & $\mathbf{2 0 0 6}$ & $\mathbf{2 0 0 7}$ & $\mathbf{2 0 0 8}$ & $\mathbf{2 0 0 9}$ & $\mathbf{2 0 1 0}$ & $\mathbf{2 0 1 1}$ & $\mathbf{2 0 1 2}$ \\
\hline Energy & 53.17 & 56.24 & 55.25 & 59.35 & 57.93 & 54.84 & 55.34 \\
Non Energy & 46.83 & 43.76 & 44.75 & 40.65 & 42.07 & 45.16 & 44.66 \\
\hline
\end{tabular}

Sumber : Kementerian Keuangan RI

Tabel di atas menunjukkan adanya ketimpangan atas peran subsidi dalam memberikan stimulus dalam perekonomian dengan andil yang besar terhadap gas rumah kaca. Penelitian ini bertujuan untuk melihat bagaimana dampak dari pengurangan subsidi energi dari pemerintah Indonesia terhadap penurunan gas $\mathrm{CO} 2$, sehingga bisa memberikan andil atas mitigasi dari perubahan iklim. Selain itu, bagaimana dampak dari penurunan subsidi energi terhadap perekonomian.

Menjadi sebuah negara dengan pendapatan yang rendah dan anggaran yang terbatas, membuat masalah adaptasi dan mitigasi dampak negatif perubahan iklim menjadi semakin sulit (Stern, 2006). Dengan populasi lebih dari 230 juta penduduk pada tahun 2013 yang menempatkan Indonesia pada posisi ke-4 dilihat dari jumlah penduduk, maka keberadaan Indonesia menjadi sangat penting dalam konteks penentuan kebijakan perubahan iklim secara global, karena pertumbuhan emisi karbon per kapita telah meningkat sebanyak sepuluh kali lipat dari semenjak tahun 1950-an, hingga pada tahun 2002 emisi karbon per kapita Indonesia telah mencapai 0.39 metrik ton, walaupun masih di bawah ratarata total emisi gas per kapita secara global (Marland et al., 2005), artinya jika tidak ada tindakan nyata, maka hanya tinggal menunggu waktu saja sebelum emisi gas per kapita Indonesia akan melebihi rata-rata emisi gas per kapita global.

Indonesia adalah salah satu Negara penghasil CO2 tertinggi di dunia. Sejak 2004, Indonesia termasuk kedalam 25 terbesar untuk CO2 dari sektor FOSIL FUEL. Jika emisi dari deforestasi dimasukkan Indonesia menjadi 3-5 emitor terbesar di dunia (Resosudarmo et al, 2008).Isu pengurangan subsidi FOSIL FUEL berhasil menjadi tema pertikaian seru dalam masa tahun anggaran 2013 di Indonesia. Hal ini merupakan tindak lanjut dari penundaan kenaikan FOSIL FUEL pada bulan Maret-April tahun 2012 lalu. 
Dalih Pemerintah melakukan pengurangan subsidi FOSIL FUEL merupakan cerminan dari asumsi ekonomi makro Indonesia yang dipengaruhi oleh dampak krisis global yang tak berkesudahan. Melihat kondisi domestik di Indonesia kini, isu pengurangan subsidi FOSIL FUEL kembali mencuat ke permukaan setelah sebelumnya pada tahun anggaran 2012 subsidi FOSIL FUEL melonjak naik dari pagu 40 juta Kiloliter menjadi 45,2 juta Kiloliter. Hal ini cukup untuk menguras anggaran APBN hingga anggaran subsidi membengkak $154,22 \%$ dari pagu subsidi FOSIL FUEL di APBN 2012. Hal ini menjadi dalih Pemerintah yang membentuk alasannya mengapa APBN-P 2012 bisa defisit anggaran. Meski Indonesia bukan negara sejahtera (welfare state), jenis dan kuantitas subsidi yang dialokasikan pemerintah bagi masyarakat tidak bisa dibilang kecil. Nilai subsidi 2012 mencapai $\mathrm{Rp}$ 346,4 triliun atau 34,33 persen dari belanja pemerintah pusat. Tak kurang dari 61,17 persen dari total subsidi dialokasikan untuk FOSIL FUEL (Rp 211,9 triliun) dan 27,30 persen untuk listrik (Rp 94,6 triliun). Subsidi pangan, pupuk, benih, kredit program, dan lain-lain hanya $\operatorname{Rp} 39,9$ triliun atau 11,53 persen dari total subsidi (Pradipyo, 2013).

Data Kementerian Energi dan Sumber Daya Mineral menunjukkan, proporsi FOSIL FUEL bersubsidi dinikmati oleh: 1) pemilik mobil (53 persen) dibandingkan pemilik motor (47 persen); 2) masyarakat di Jawa dan Bali (59 persen); dan 3) angkutan darat (89 persen). Tercatat 25 persen rumah tangga berpenghasilan tertinggi menikmati 77 persen subsidi FOSIL FUEL dibandingkan 25 persen rumah tangga berpenghasilan terendah yang hanya menikmati 15 persen subsidi FOSIL FUEL (Kementerian Keuangan, 2012).

\section{METODE PENELITIAN}

Kerangka pikir secara umum dan juga prinsip peran kementerian keuangan dalam mengatasi perubahan iklim dapat diilustrasikan pada Gambar 1. Prinsip penting yang tergambar adalah tujuan utama kebijakan fiskal yaitu membantu mencapai tujuan utama dari pembangunan ekonomi yang bersifat pro-growth, pro-job, dan pro-poor. Melalui instrumeninstrumen fiskalnya kementerian keuangan mencoba mewujudkan pembangunan ekonomi yang efisien (pro growth), mengurangi pengangguran (pro job), dan juga menjaga agar pembangunan yang terjadi juga berkeadilan (pro-poor).

QE Journal | Vol.05 - No. 02 June 2016 - 79 


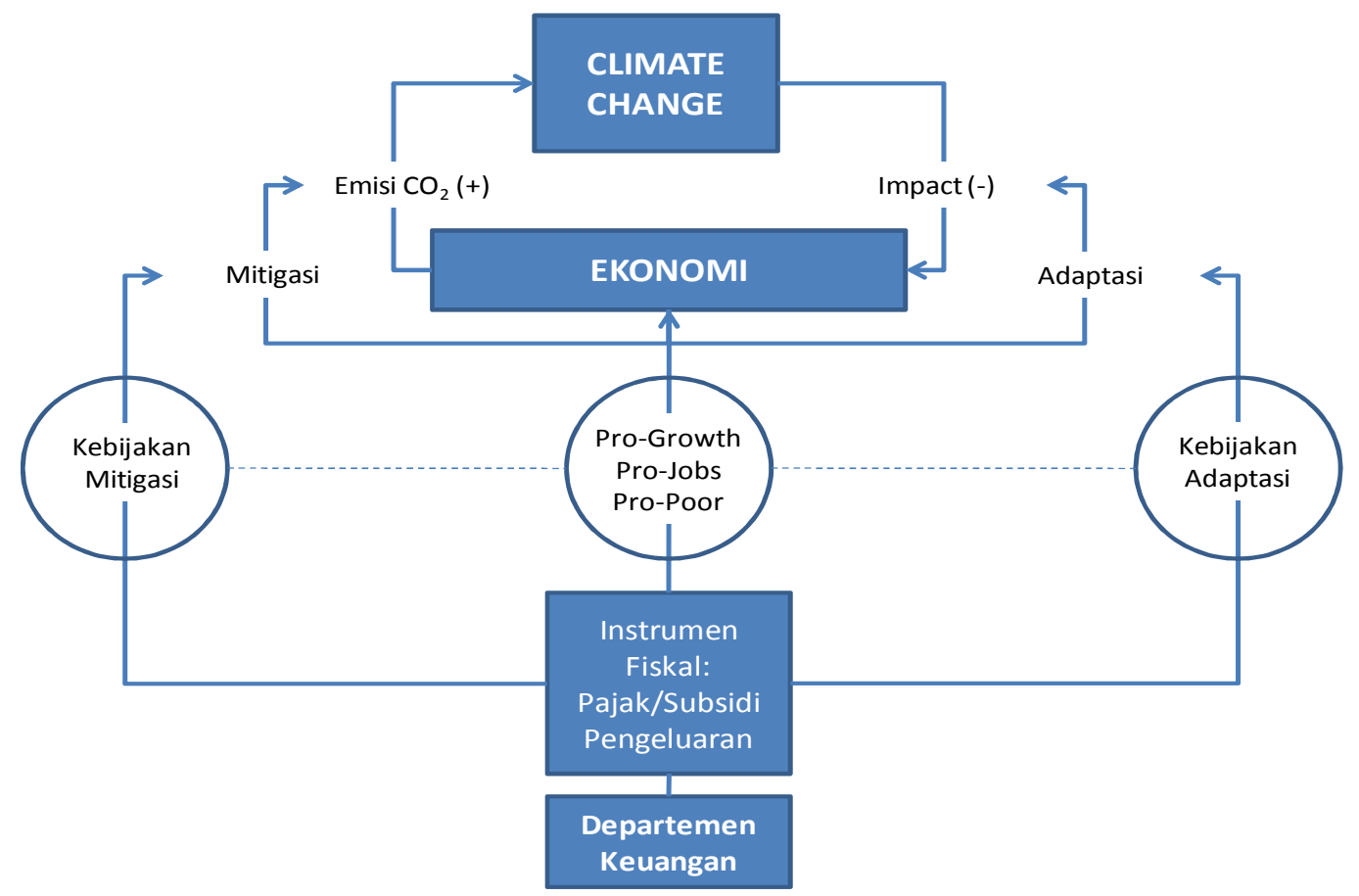

Gambar 1. Prinsip Peran Instrument Fiskal Dalam Mengatasi Masalah Perubahan Iklim

Pembangunan ekonomi turut menyumbang emisi CO2 dan pada akhirnya turut berkontribusi pada pemanasan global. Perubahan iklim kemudian berdampak negatif kepada perekonomian (impact). Dampak ini dapat berupa kenaikan permukaan air laut, variabilitas iklim yang semakin tinggi, kenaikan temperatur, serta curah hujan yang semakin tidak terprediksi.

Kementerian keuangan melalui instrumen fiskal-nya bisa mempengaruhi alur proses bisnis-as-usual tersebut dengan mempengaruhi jumlah emisi CO2 melalui kebijakan mitigasi, serta membantu proses adaptasi perekonomian terhadap perubahan iklim. Prinsip yang penting dalam intervensi ini adalah baik kebijakan mitigasi dan kebijakan adaptasi yang diperani oleh kementerian keuangan tidak bertentangan dengan peran utama kementerian keuangan untuk menjaga pembangunan ekonomi yang pro-growth, pro-jobs, pro-poor dan pro-climate change. Salah satu dari tujuan utama kajian ini adalah mencari berbagai alternatif instrument kebijakan fiskal yang dapat memenuhi prinsip penting ini. 


\section{Struktur Model AGEFIS-2}

Metodologi yang akan digunakan dalam pengkajian ini yaitu: Analisis economy-wide (CGE) model. Analisis economy-wide (Computable General Equilibrium - CGE) model akan digunakan untuk mengeksplorasi berbagai alternatif instrumen kebijakan fiskal yang dapat mengatasi climate change dan juga menjaga akan tujuan pembangunan nasional yang utama, yaitu pertumbuhan ekonomi yang efisien, menciptakan lapangan kerja, serta berkeadilan tetap terjaga. Karena keterbatasan dalam metodologi, analisis economy-wide model akan berfokus pada mitigasi perubahan iklim.

Model yang akan dikembangan dan digunakan adalah model AGEFIS-2, sebuah pengembangan model AGEFIS (Lihat Yusuf dkk, 2008). Model CGE yang dikhususkan untuk menganalisa kebijakan-kebijakan terkait mitigasi perubahan iklim. Deskripsi detail dari struktur model AGEFIS ini akan dibahas pada bagian selanjutnya. Untuk pengkajian ini, model AGEFIS akan dikembangkan menjadi model AGEFIS-2 dengan dimodifikasi sesuai dengan kebutuhan analisis serta data-datanya akan diperbaharui jika memungkinkan.

Ekstensi model AGEFIS menjadi AGEFIS-2 adalah sebagai berikut:

1. Disagregasi sektor yang lebih detail terutama menyangkut berbagai sumber energi baik yang non-renewable dan carbon-emmiting dan juga non-renewable energi sepanjang datanya memungkinkan.

2. Struktur produksi dibuat memungkinkannya substitusi antara energi dan antara energi dengan input lainnya (misalnya input primer atau kapital).

3. Rumah tangga akan didisagregasi untuk memungkinkan analisis distribusi.

4. Dimasukannya emisi karbondioksida secara eksplisit ke dalam model

5. Dimasukannya carbon accounting ke dalam model

Berbagai alternatif instrument fiskal serta kombinasinya (termasuk kombinasi revenue-recycling-nya) akan dianalisis untuk kemudian dikaji kelebihan dan kekurangannya sesuai dengan dampaknya terhadap perekonomian (Economy, growth, employment), lingkungan (emisi CO2), serta keadilan (ketimpangan dan kemiskinan). Dari situ bisa ditentukan instrumen dan kombinasi instrumen mana yang dianggap paling baik. 


\section{Skenario Simulasi}

Isu dampak negatif dari subsidi energi bukanlah hal yang baru. Telah banyak literatur dan penelitian yang mencoba mengelaborasi hal ini. Saat ini subsidi energi dianggap sudah tidak relevan lagi penerapannya (The Economist, 2009). Subsidi harga bahan bakar minyak dinilai tidak tepat sasaran, karena lebih banyak dinikmati oleh masyarakat berpendapatan menengah ke atas terutama yang bermukim di daerah perkotaan. Selanjutnya, setelah Indonesia menjadi net-importer minyak bumi sejak 2004, subsidi FOSIL FUEL dikhawatirkan akan meningkatkan ketergantungan akan energi dari suplai luar negeri yang mana relative beresiko. Subsidi energi juga hanya akan mendorong pemborosan konsumsi energi domestik dan menjadi disinsentif bagi pengembangan energi baru dan terbarukan, yang pada akhirnya berdampak buruk terhadap energy security.

Dari sudut pandang lingkungan, subsidi bahan bakar fossil hanya akan memperburuk kondisi lingkungan dan suhu bumi. Mensubsidi bahan bakar fosil sama artinya dengan mendukung penambahan emisi gas rumah kaca yang akan menyebabkan pemanasan global dan pada akhirnya penyebab dari adanya perubahan iklim.

Economist (2013) menekankan bahwa kurang dari 15\% emisi karbon global sekarang disebabkan oleh efek berlebihan dari kebijakan memberikan subsidi energi, bahkan menurut penelitian IMF. Economist juga menekankan bila terjadi penurunan atas kebijakan tersebut akan segera mencapai target pengurangan karbon untuk tiap negara dan pada dekade berikutnya, dimana dalam jangka panjang penurunan subsidi akan meningkatkan perekonomian. Oleh karena itu, penghapusan subsidi energi harus menjadi concern utama para pengambil kebijakan, khususnya di kementerian keuangan, dalam upaya mitigasi perubahan iklim dengan menggunakan instrument fiskal.

Skeario yang digunakan dalam penelitian ini adalah dengan mengaplikasikan adanya kenaikan harga premium pada saat harga Rp 4500 menjadi $\mathrm{Rp}$ 6500, dimana pada dasarnya subsidi untuk fosil fuel berkurang sebesar Rp 2000 untuk tiap liternya. pengurangan subdisi ini tentu diharapkan berdampak terhadap semua sektor dalam perekonomian 
dan sekaligus memberi dampak atas produksi $\mathrm{CO} 2$ dari tiap aktivitas ekonomi.

\section{HASIL DAN PEMBAHASAN}

\section{Dampak Simulasi Terhadap Emisi CO2}

Kenaikan harga FOSIL FUEL atau menurunkan subsidi FOSIL FUEL menyebabkan penurunan permintaan akan FOSIL FUEL oleh rumah tangga sebesar $7.4 \%$ relatif terhadap baseline dengan penurunan konsumsi FOSIL FUEL sebesar 5,77\% relatif terhadap baseline. Hal ini mengisyaratkan adanya penurunan konsumsi FOSIL FUEL sebagai akibat dari kenaikan harga. Output semua sektor ekonomi turun akibat dari adanya penurunan subsidi dari FOSIL FUEL, hal ini terjadi karena FOSIL FUEL diperlukan baik secara langsung ataupun tidak langsung dalam semua aktivitas perekonomian.

Penurunan subsidi ini berdampak pada penurunan hampir semua output untuk tiap sektor dalam ekonomi. Tabel 1 menunjukkan terjadinya penurunan output paling besar setelah adanya penurunan subsidi. Hasilnya tidak mengejutkan, terutama dampak yang besar terjadi pada sektor transportasi yang banyak menggunakan energi minyak, selain itu pembangkit listrik juga mendapatkan dampak terbesar untuk penurunan output.

Tabel 2. Dampak Terbesar dari dampak Pengurangan Subsidi pada Output Sektor

\begin{tabular}{clc}
\hline No & Output & Percentage Change \\
\hline 1 & BBM & -14.49 \\
2 & AIRTR & -5.12 \\
3 & LNDTR & -2.23 \\
4 & PLTP & -2.22 \\
5 & PLTD & -2.22 \\
6 & PLTGU & -2.22 \\
7 & PLN & -2.22 \\
8 & PLTA & -2.22 \\
9 & PLTU & -2.22 \\
10 & PLTG & -2.22 \\
\hline
\end{tabular}

Sumber: Hasil Perhitungan Model

QE Journal | Vol.05 - No. 02 June 2016 - 83 
Penurunan subsidi memberikan penurunan output seperti ditunjukkan pada tabel di atas. Penurunan output tentunya memberikan penurunan $\mathrm{CO} 2$ yang ada seiring dengan dibuatnya ouput pada sebuah proses produksi. Tabel 3 memberikan gambaran atas penurunan $\mathrm{CO} 2$ untuk 10 sektor terbesar yang terkena dampak dari penurunan subsidi FOSIL FUEL. Sektor FOSIL FUEL memberikan penurunan CO2 terbesar karena mengalami penurunan output terbesar atas dampak langsung kenaikan fosil fuel. Sektor gas alam (NATGAS) mengalami penurunan akibat dari industri fosil fuel juga menggunakan input dari gas alam. Sektor-sektor lain seperti transportasi udara (AIRTR), industri air, makanan perbankan dan perikanan juga mengalami penurunaan output $\mathrm{CO} 2$ terbesar.

Sektor Geothermal mengalami kenaikan. Hal ini memberikan penjelasan bahwa sumber energi ini menjadi relatif lebih murah, tentunya di luar biaya pembangunan pabrik, sehingga terdapat pergeseran input energi terhadap geotermal walaupun relatif tidak besar. Bila dilihat dari penurunan output yang terkecil, ternyata terdapat coal. Walaupun turun outputnya, tetapi sangat kecil. Hal ini karena coal merupakan substitusi energi bagi fosil fuel terutama untuk industri, seperti industri listrik.

Tabel 3. Dampak Terbesar Pengurangan Subdisi terhadap Output CO2

\begin{tabular}{cclc}
\hline No & & \multicolumn{1}{c}{ CO2 } & Percentage Change \\
\hline 1 & BBM & -52.40 \\
2 & NATGAS & -9.98 \\
3 & WATER & -7.88 \\
4 & AIRTR & -7.80 \\
5 & FOOD & -7.57 \\
6 & BANK & -7.47 \\
7 & FISHR & -7.39 \\
8 & SERV & -7.28 \\
9 & REST & -7.27 \\
10 & LIVEST & -7.25 \\
\hline
\end{tabular}

Sumber: Hasil Perhitungan Model

Akibat dari penurunan output mengakibatkan penurunan dari emisi $\mathrm{CO} 2$ per sektor atau secara umum sebesar $3,74 \%$ dari baseline. Hal ini mempunyai konsekuensi biaya yang cukup tinggi. Tabel 3 merupakan hasil simulasi yang disebabkan oleh penurunan subsidi fosil fuel. Perekonomian mengalami penurunan sebesar $1.25 \%$ dari baseline. 
Penurunan ini seiringa dengan turunnya tingkat konsumsi riil dari masyarakat yang menjadi alasan kenapa adanya penurunan terhadap GDP. Hal menarik lainnya adalah adanya penurunan terhadap harga. Consumer price index mengalami penurunan sebesar $0.19 \%$ dari baseline demikian juga tingkat harga konsumsi juga turun sebesar $3.74 \%$ dari baseline. Dengan kata lain terjadi penurunan kinerja ekonomi diikuti dengan penurunan harga. Walaupun perubahan ini merupakan persentase perubahan terhadap baseline, tetapi hal ini menunjukkan adanya upaya untuk menurunkan subsidi dengan dalih untuk menurunkan konsumsi fosil fuel mempunyai biaya seiring dengan bonus penurunan atas gas rumah kaca.

Tabel 4. Perubahan Makro Ekonomi Indonesia

\begin{tabular}{llr}
\hline \multicolumn{1}{c}{ Deskripsi } & \multicolumn{1}{c}{ Variabel Makro } & Hasil Simulasi \\
\hline consumers price index & cpi & -0.19 \\
net indirect tax (change) & dellNDTAX & 61196.30 \\
delSAV (change) & delSAV & 3616.60 \\
delSAVH (change) & delSAVH & -4232.95 \\
govenrment saving (change) & delSG & 43978.65 \\
govenrment expenditure & egc & -14.81 \\
price of consumption & pcon_c & -0.19 \\
total emissions & xco_ue & -3.74 \\
real consumption & xcon_c & -2.41 \\
gdp & xgdpexp2 & -1.25 \\
\hline
\end{tabular}

Sumber: Hasil Perhitungan Model

Dari sisi anggaran pemerintah, terjadi kenaikan simpanan dari subsidi pemerintah sebesar 44 trilyun rupiah. Hal ini pemerintah mendapatkan sisa anggaran dari biasanya untuk membayar subsidi.

\section{SIMPULAN DAN SARAN}

Berdasarkan hasil simulasi untuk menurunkan subsidi dengan tujuan untuk menurunkan gas rumah kaca dari penggunaan fosil fuel yang berlebihan memberikan beberapa kesimpulan sebagai berikut:

1. Fosil fuel sebagai sumber dari gas $\mathrm{CO} 2$ mempunyai peran yang besar terhadap perekonomian. Hal ini terlhat dari penurunan

QE Journal | Vol.05 - No. 02 June 2016 - 85 
output untuk hampir dari semua sektor sebagai dampak dari penurunan subsidi untuk fosil fuel. Makro ekonomi juga menunjukkan tingkat yang meresahkan, dilihat dari penurunan tinkat pertumbuhan ekonomi relatif terhadap baselin dan tingkat konsumsi riil rumah tangga relatif terhadap baseline.

2. Menurunkan subsidi terhadap fosil fuel mempunyai konsekuensi yang tinggi. Betul terjadi penurunan emisi yang cukup besar sebagai dampak penurunan konsumsi fosil fuel akibat harga fosil fuel yang lebih mahal. Konsekuensi tersebut dilihat dari pertumbuhan ekonomi yang turun, kesejahteraan rumah tangga yang juga turun dilihat dari tingkat konsumsi riil yang turun.

\section{DAFTAR PUSTAKA}

Aghion, Philippe and Bolton, Patrick (1997), A Theory of Trickle Down Growth and Development, Review of Economic Studies (1997) 64, 151-172.

Fatah, et.al. (2012), Economic Growth, Political Freedom and Human Development: China, Indonesia and Malaysia, International Journal of Business and Social Science, Vol. 3 No. 1; January 2012.

Ismal, Rifki (2011), Assessing Economic Growth and Fiscal Policy in Indonesia, Journal of Economic and Business, No. 1 (53-71), Vol. XIV.

Stiglitz, J. (1996), Some Lessons from East Asian Miracle, The World Bank Research Observer, Available at: URL:http://sp.ec.tku.edu.tw/QuickPlace/113922qp/Main.nsf/\$defau ltview/16C4BC965C792B624825725600599359/\$File/Stiglitz1996.pdf? OpenElement, AcessDate: November 28th, 2013

Ministry of Finance of Indonesia, DATA POKOK APBN 2006-2012.

Halkos, George (2012), The Impact of Government Expenditure on the Environment: An Empirical Investigation. Munich Personal RePEc Archive (MPRA) Paper No. 39957, Online at http://mpra.ub.unimuenchen.de/39957/. 
Ghali, K.H., 1998. Government size and economic growth: evidence from a multivariate cointegration analysis. Applied Economics 31, 975-987.

Stern, David I, (2003), International Society for Ecological Economics, Internet Encyclopaedia of Ecological Economics, The Environmental

Kuznets Curve, available at http://isecoeco.org/pdf/stern.pdf

Sim, N.C.S., 2006. Environmental Keynesian Macroeconomics: Some further discussion. Ecological Economics 59, 401-405.

Climate Change and Fiscal Policy: A Report for APEC, 2010

Yusuf, Arief A. and Budy P. Resosudarmo (2007), "On the Distributional Effect of Carbon Tax in Developing Countries: The Case of Indonesia", Papers No. EEN0706, Economics and Environment Network, the Australian National University. 


\section{Lampiran}

Tabel L.1. Daftar Sektor Dalam AGEFIS-2

\begin{tabular}{|c|c|c|}
\hline No. & Set & Nama Sektor \\
\hline 1 & CROPS & Pertanian Tanaman Pangan \\
\hline 2 & OTHCRP & Pertanian Tanaman Lainnya \\
\hline 3 & LIVSTK & Peternakan dan Hasil-hasilnya \\
\hline 4 & FOREST & Kehutanan dan Perburuan \\
\hline 5 & FISH & Perikanan \\
\hline 6 & COAL & Batubara \\
\hline 7 & OlL & Minyak Bumi \\
\hline 8 & NATGAS & Gas Bumi \\
\hline 9 & GEOTHE & Panas Bumi \\
\hline 10 & MINE & Biji Logam/lainnya \\
\hline 11 & OTHMINE & Pertambangan dan Penggalian Lainnya \\
\hline 12 & FOOD & Industri Makanan, Minuman dan Tembakau \\
\hline 13 & TEXTILE & Industri Pemintalan, Tekstil, Pakaian dan Kulit \\
\hline 14 & WOODP & Industri Kayu \& Barang Dari Kayu \\
\hline 15 & PAPER & Industri Kertas, Percetakan, Alat Angkutan dan Barang Dari Logam dan Industri \\
\hline 16 & BBM & Hasil olahan minyak \\
\hline 17 & CHEM & Industri Kimia Lainnya \\
\hline 18 & PLN & Pembangkit Listrik Non-PLTA \\
\hline 19 & PLTA & Pembangkint Listrik Tenaga Air \\
\hline 20 & UTIL & Gas dan air minum \\
\hline 21 & CONSTRU & Konstruksi \\
\hline 22 & TRADE & Perdagangan \\
\hline 23 & RESTAU & Restoran \\
\hline 24 & HOTEL & Perhotelan \\
\hline 25 & LNDTRAN & Angkutan Darat \\
\hline 26 & AIRTRAN & Udara \\
\hline 27 & WTRTRAN & Air \\
\hline 28 & COMMUN & Komunikasi \\
\hline 29 & TRASERV & Jasa Penunjang Angkutan, dan Pergudangan \\
\hline 30 & BANK & Bank dan Asuransi \\
\hline $\begin{array}{l}31 \\
32\end{array}$ & $\begin{array}{l}\text { ESTATE } \\
\text { GOVSER }\end{array}$ & $\begin{array}{l}\text { Real Estate dan Jasa Perusahaan } \\
\text { Pemerintahan dan Pertahanan, Pendidikan, Kesehatan, Film dan Jasa Sosial } \\
\text { Lainnya }\end{array}$ \\
\hline 33 & OTHSER & Jasa Perseorangan, Rumah tangga dan Jasa Lainnya \\
\hline
\end{tabular}

QE Journal | Vol.05 - No. 02 June 2016 - 88 